\title{
Phase transformations during continuous heating: effect of Sn addition on the microstructure of Ti-13Mo alloy
}

\author{
M.G. de Mello ${ }^{\mathrm{a}}$, F.H. da Costa ${ }^{\mathrm{a}}$, R. Caram ${ }^{\mathrm{a}}{ }^{*}$

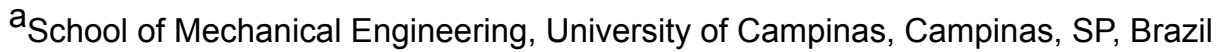 \\ *caram@fem.unicamp.br
}

\begin{abstract}
$\underline{\text { Abstract }}$
The addition of Sn to the Ti-Mo system can diminish the formation of $\omega$ phase and slow down the precipitation kinetics of $\alpha$ phase due to the low atomic diffusivity of Sn atoms in Ti. To explore $\alpha$ phase precipitation in Ti-13Mo and Ti-13Mo-6Sn (wt.\%) alloys, differential scanning calorimetry (DSC) was applied using different heating rates to determine $\omega$ phase dissolution, $\alpha$ phase precipitation and $\beta$ transus temperatures. The DSC results were then used to determine the aging heat treatment temperatures. Samples were heat-treated at $600{ }^{\circ} \mathrm{C}$ for $1 \mathrm{~h}$ and $24 \mathrm{~h}$ to examine microstructure features. The addition of Sn to Ti-13Mo alloy was found to increase the $\beta$ phase lattice parameter, increasing $\beta$ transus temperatures and resulting in microstructures with heterogeneous and coarser $\alpha$ phase precipitation.
\end{abstract}

\section{Introduction}

Metastable $\beta$ Ti alloys are being employed increasingly in several fields, from medicine to the aerospace industry, thanks to their unique features, such as enhanced biocompatibility, higher corrosion resistance and exceptional mechanical behavior [1-2]. Beta type Ti alloys are obtained when sufficient amounts of $\beta$ stabilizing elements, for instance $\mathrm{Nb}, \mathrm{Fe}$, Ta or Mo, are added to Ti [3], lowering the $\beta$ transus temperature and reducing the martensite start temperature to below room temperature. Therefore, upon quenching from temperatures in the $\beta$ field, the $\mathrm{BCC}$ titanium allotropic form, i.e., $\beta$ phase, can be fully retained at room temperature without decomposing into other phases [4]. Compared to the HCP Ti allotropic form, i.e., $\alpha$ phase, the $\beta$ phase is mechanically soft, as a direct result of the nature of its crystal structure. However, a powerful way to improve the mechanical behavior of $\beta$ type Ti alloys is through controlled precipitation of finely dispersed $\alpha$ phase in the $\beta$ matrix by means of aging heat treatment.

Solution heat-treated $\beta$ Ti alloys subjected to an aging heat treatment at intermediary temperatures can present $\beta$ phase decomposition and $\omega$ and $\alpha$ phase precipitations. This is an intricate transformation process that involves precipitation of metastable $\omega$ phase in the $\beta$ phase matrix, followed by $\alpha$ phase precipitation. During these phase transformations, $\omega$ phase plays an important role in assisting $\alpha$ phase precipitation by acting as a substrate for heterogeneous nucleation $[5,6]$.

Controlling phase transformation during aging heat treatments of $\beta \mathrm{Ti}$ alloys allows one to tailor their microstructures, and hence, their mechanical behavior. Therefore, an in-depth understanding of the course of this solid-state transformation is essential. Several analytical techniques to investigate phase transformations in $\mathrm{Ti}$ alloys are available, and one of most suitable ones is differential scanning calorimetry (DSC), which is based on enthalpy changes during the reaction [7].

Molybdenum is a powerful $\beta$ stabilizing element that is often present in a variety of high strength commercial Ti alloys, including Beta C, Beta 21S, and Ti-5553 alloys [8]. Ti-Mo based alloys are used not only in aerospace applications but also in the manufacture of biomedical implant devices, because of their biocompatibility, corrosion resistance and low elastic modulus.

Solution heat treating and rapid quenching of Ti-Mo alloys stabilizes $\beta$ phase at room temperature, but is accompanied by $\omega$ phase precipitation, which drastically reduces the ductility of Ti alloys. The precipitation of $\omega$ phase, in this case, is due to the collapse of $\{111\}$ planes of $\beta$ phase [9]. On the one hand, the $\omega$ phase is very hard, presenting high elastic modulus and precipitates of nanometric dimensions. On the other hand, this metastable phase is essential for $\alpha$ phase precipitation into the $\beta$ matrix. Adding Sn to Ti-Mo alloys is considered an effective way to control $\omega$ phase precipitation in metastable $\beta$ phase Ti alloys $[10,11]$

The microstructure and mechanical behavior of metastable $\beta$ Ti-Mo alloys are strongly dependent on their phase transformation features, which can be influenced by the addition of Sn. Therefore, the focus of this study is an investigation of the correlation between phase transformation and microstructure in a new $\beta$ Ti-Mo-Sn alloy, based on differential scanning calorimetry (DSC) and aging heat treatments. 


\section{Experimental Procedure}

Ti-Mo-Sn ingots weighing approximately $80 \mathrm{~g}$ were prepared from high chemical purity Ti, Mo and Sn in an arc furnace with a non-consumable tungsten electrode and water-cooled copper crucible in a highly pure argon atmosphere. The ingots were inverted and remelted 10 times to ensure their chemical homogeneity. Two compositions were chosen: Ti-13Mo and Ti-13Mo-6Sn (wt.\%). The arc melted ingots were encapsulated in quartz ampoules in a partial argon atmosphere, heat-treated for $24 \mathrm{~h}$ at 1000 ${ }^{\circ} \mathrm{C}$, and furnace cooled. Hot rolling was performed at $1000{ }^{\circ} \mathrm{C}$, followed by air cooling and sanding to remove the oxide layer, producing $1 \mathrm{~mm}$ thick plates that were then cut in a Struers Accutom-10 cutter. The sample's chemical composition was examined by X-ray fluorescence spectroscopy in a Shimadzu EDX-7000 energy-dispersive X-ray fluorescence spectrometer, while oxygen and nitrogen interstitial contents were determined using a LECO TC400 nitrogen/oxygen analyzer.

Microstructural analyses were carried out by scanning electron microscopy (SEM) (FEI QUANTA 650 FEG). The SEM analyses were performed on samples without chemical etching, using the backscattered electron signals to reveal contrasts in the composition of the microstructures. The sample's microstructure was also investigated by X-ray diffraction (XRD) using a PANalytical X'Pert diffractometer equipped with a PIXel X-ray detector and $\mathrm{CuK}_{\alpha}$ radiation $(\lambda=1.5406 \AA)$ operating at $40 \mathrm{kV}$ and $30 \mathrm{~mA}$. The $\beta$ phase lattice parameters were estimated based on Rietveld refinement [12], using the MAUD (Materials Analysis using Diffraction) program [13].

Differential scanning calorimetry (DSC) was carried out in a Netzsch STA 409 thermal analyzer, applying scan rates of 5, 10 and $30{ }^{\circ} \mathrm{C} / \mathrm{min}$ in a dynamic high purity argon atmosphere. Aging heat treatments were carried out at $600{ }^{\circ} \mathrm{C}$ for $1 \mathrm{~h}$ and $24 \mathrm{~h}$, using a heating rate of $250^{\circ} \mathrm{C} / \mathrm{min}$. All the experiments were performed in an inert atmosphere.

\section{Results and Discussion}

The chemical analysis revealed that the experimental compositions were close to the nominal ones. The Mo content measured in the Ti-13Mo was found to be $13.2 \pm 0.1 \mathrm{wt} . \%$, while the amounts of oxygen and nitrogen were $0.22 \pm 0.02$ and $0.014 \pm 0.006$ wt. $\%$, respectively. The Ti-13Mo- 6 Sn alloy showed similar results, with Mo and Sn contents of $13.04 \pm 0.03$ wt. $\%$ and $6.5 \pm 0.1$ wt. $\%$, respectively. Oxygen and nitrogen contents were $0.21 \pm 0.02$ wt.\% and $0.008 \pm 0.002$ wt. $\%$, respectively. All the interstitial levels were in line with the ASTM-B-364-83 standard.

Samples of the Ti-13Mo and Ti-13Mo-6Sn (wt.\%) alloys were solution heat-treated at temperatures in the $\beta$ field (ST) and water quenched (WQ). Figure 1 shows the XRD pattern of ST/WQ Ti-13Mo and Ti-13Mo-6Sn samples. These patterns suggest that the resulting microstructures consist essentially of $\beta$ phase. An in-depth analysis of the XRD pattern of the Ti-13Mo alloy suggests a low volumetric fraction of athermal $\omega$ phase precipitation. This finding is in good agreement with results reported by Cardoso et al. [14]. The XRD pattern of the Ti-13Mo-6Sn alloy in the same condition showed only $\beta$ phase peaks. According to data in the literature, the addition of $6 \mathrm{wt} . \%$ of Sn can reduce athermal $\omega$ phase formation after solution in the $\beta$ field, followed by water quenching [10,11]. Williams et al. evaluated the microstructural effects of adding Sn to Ti-Mo alloys [15]. Their findings led them to conclude that the addition of Sn destabilized the $\omega$ phase as its volume fraction decreased with Sn content. They also found that adding $\mathrm{Sn}$ increases the $\beta$ phase lattice parameter and decreases the misfit between $\omega$ and $\beta$ phases.

To determine the $\beta$ phase lattice parameter in Ti-13Mo and Ti-13Mo-6Sn alloys, their XRD data were subjected to Rietveld refinement using the MAUD program [13]. The BCC arrangement of pure Ti is unstable at room temperature; hence, its lattice parameter can only be estimated. Aurelio et al. computed a series of results on the Ti-V system described in the literature, correlating them with the compositional dependence of the $\beta$ phase lattice parameters [16]. Based on the assumption that the lattice parameter is linearly dependent on the $\mathrm{V}$ content, they estimated the lattice parameter of pure Ti $\beta$ phase as $0.3282( \pm 0.0002) \mathrm{nm}$. Refinement results indicate that the $\beta$ phase lattice parameter of the Ti-13Mo alloy is 0.32618 while that of the Ti-13Mo-6Sn alloy is 0.32767 . The atomic radii of $\mathrm{Ti}$, Mo and $\mathrm{Sn}$ can be used to explain the lattice parameters of these alloys. While the atomic radius of Ti is close to $0.147 \mathrm{~nm}$, that of Mo is smaller $(0.136 \mathrm{~nm})$ and that of Sn is higher $(0.151 \mathrm{~nm})$ [17]. Therefore, the addition of Mo was expected to decrease the $\beta$ phase lattice parameter in ST/WQ samples, while the addition of Sn would increase this parameter.

Figure 2 shows the DSC curves plotted at different heating rates $\left(5,10\right.$ and $\left.30^{\circ} \mathrm{C} / \mathrm{min}\right)$ in an argon atmosphere. The sample's initial condition also corresponds to solution heat treatment and water quenching. According to the literature, the higher the heating rate the more intense the peaks and the higher the phase transformation temperatures [18]. On the other hand, the peaks are more numerous at lower heating rates. The heating rate of $10{ }^{\circ} \mathrm{C} / \mathrm{min}$ was chosen as the best compromise between sensitivity and resolution of the curves for the remaining experiments. 

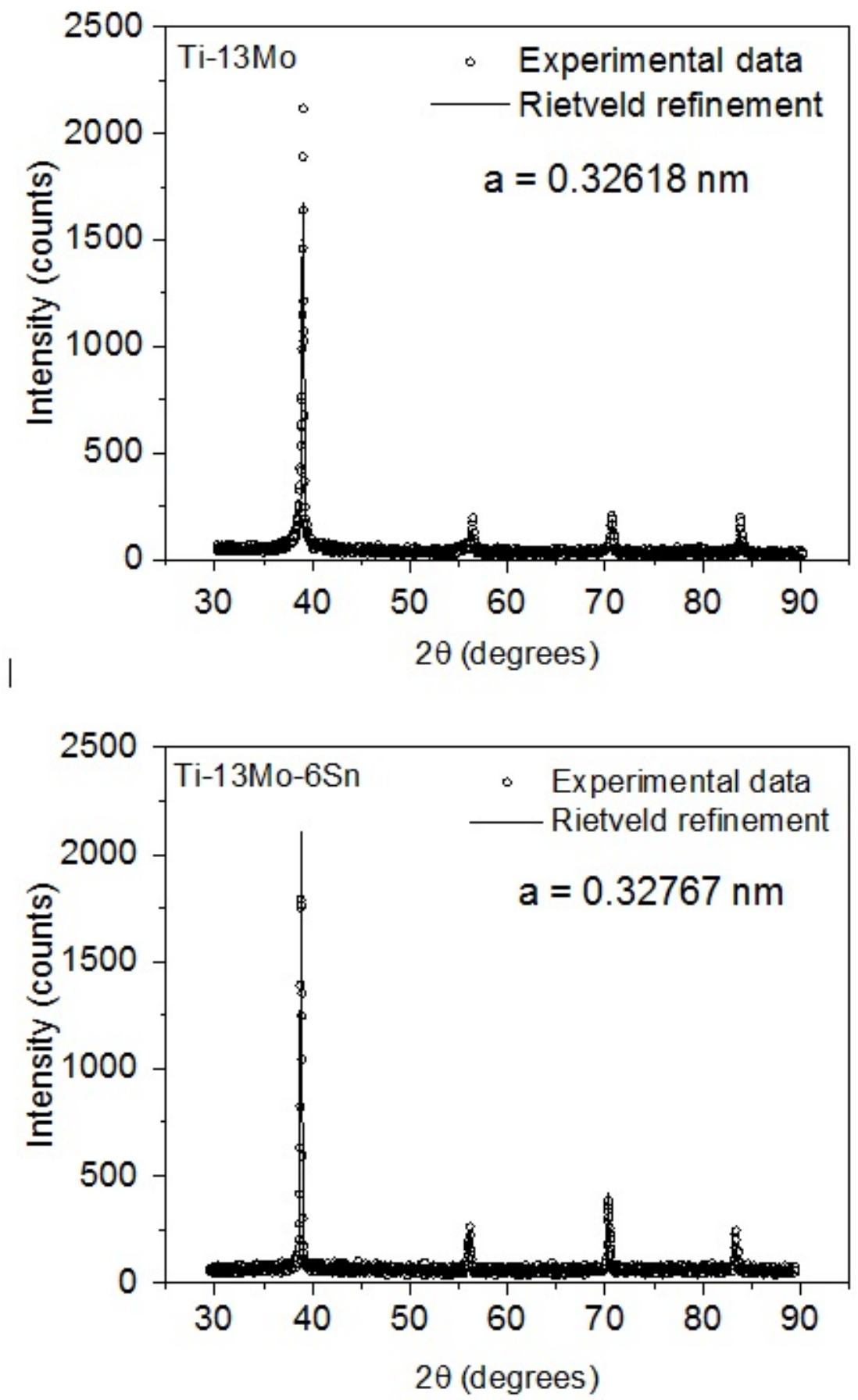

Figure 1. Experimental and computed values of XRD patterns of Ti-13Mo and Ti-13Mo-6Sn samples after Rietveld refinement.

Upon heating, the DSC curve of the Ti-13Mo alloy shows an exothermic peak at around $600{ }^{\circ} \mathrm{C}$, which corresponds to $\alpha$ phase precipitation. Also, an endothermic peak occurring before the $\alpha$ phase precipitation was detected and identified as isothermal $\omega\left(\omega_{\text {iso }}\right)$ phase dissolution. These DSC results suggest that $\omega_{\text {iso }}$ phase dissolution occurs before the onset of $\alpha$ phase precipitation, which means that $\alpha$ phase precipitation assisted by $\omega_{\text {iso }}$ phase is connected with regions of distinct compositions that may have remained after the dissolution of $\omega_{\text {iso }}$ phase precipitates. During the growth of $\omega_{\text {iso }}$ phase, Mo becomes segregated in the vicinity of precipitates, leading to Mo-poor cores, which favors $\alpha$ phase precipitation. The last endothermic peak corresponds to $\alpha \rightarrow \beta$ transformation. Based on the first derivative of the DSC curve, the $\beta$ transus temperature of the Ti-13Mo alloy was estimated to be $769^{\circ} \mathrm{C}$. Based on a linear regression analysis, Yolton et al. created a model to determine the effect of alloying elements on the $\beta$ transus temperature, which is based on the disappearing method [19]. When this model is applied to the Ti-13Mo alloy, it yields a temperature of $772{ }^{\circ} \mathrm{C}$, which is consistent with the experimental value found in this study.

The addition of Sn to the Ti-13Mo alloy reduced the $\alpha$ phase precipitation peak. This transformation was hampered mainly by the slow atomic diffusion rate of $\mathrm{Sn}$ in Ti. When the $30^{\circ} \mathrm{C} / \mathrm{min}$ heating rate was applied, no evidence was found of the $\alpha$ phase precipitation peak. Sn was found to increase the $\beta$ transus temperature by approximately $30{ }^{\circ} \mathrm{C}$ when compared to that of the Ti13Mo alloy. 

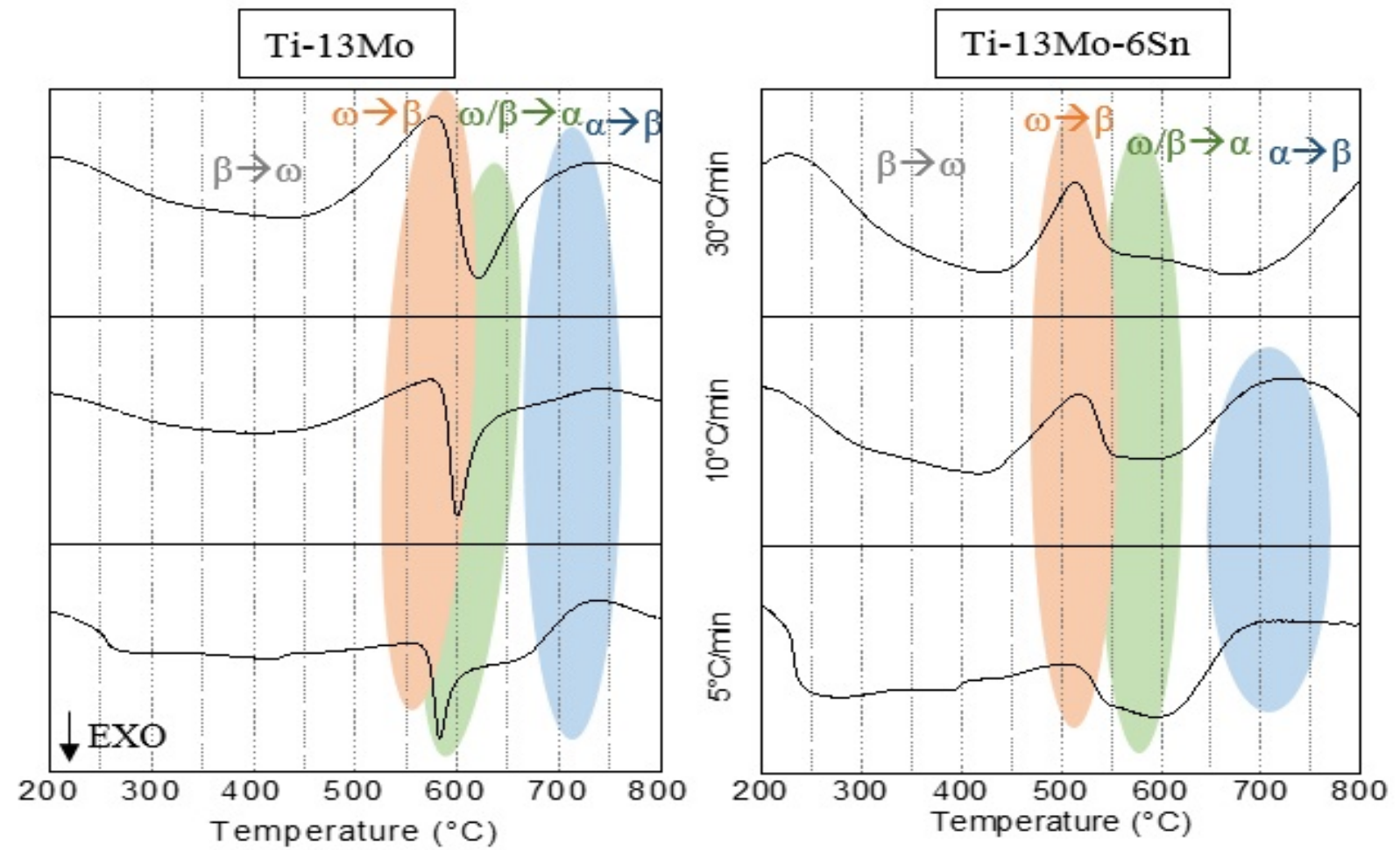

Figure 2. DSC heat flow curves corresponding to the first heating cycle applied to Ti-13Mo and Ti-13Mo-6Sn alloys using heating rates of 5, 10 and $30^{\circ} \mathrm{C} / \mathrm{min}$.

After the DSC analyses, the Ti-13Mo and Ti-13Mo-6Sn samples were also aged at $600{ }^{\circ} \mathrm{C}$ for $1 \mathrm{~h}$ and $24 \mathrm{~h}$ in order to check $\alpha$ phase precipitation. The samples were subjected to a heating rate of $250{ }^{\circ} \mathrm{C} / \mathrm{min}$. Figure 3 shows the microstructures after $600{ }^{\circ} \mathrm{C} / 1 \mathrm{~h}$ heat treatment. The results suggest that the addition of Sn led to relatively coarse $\alpha$ phase precipitation. Although Sn is considered a neutral element, it suppresses the formation of metastable phases, thereby affecting heterogeneous $\alpha$ phase nucleation. After rapid heating to $600{ }^{\circ} \mathrm{C}$, the reduced volume fraction of $\omega_{\text {iso }}$ phase affected $\alpha$ phase precipitation. Also, the atomic diffusivity of $\mathrm{Sn}$ in $\mathrm{Ti}$ is very limited, which contributes to the formation of relatively large and sparse $\alpha$ phase precipitates.

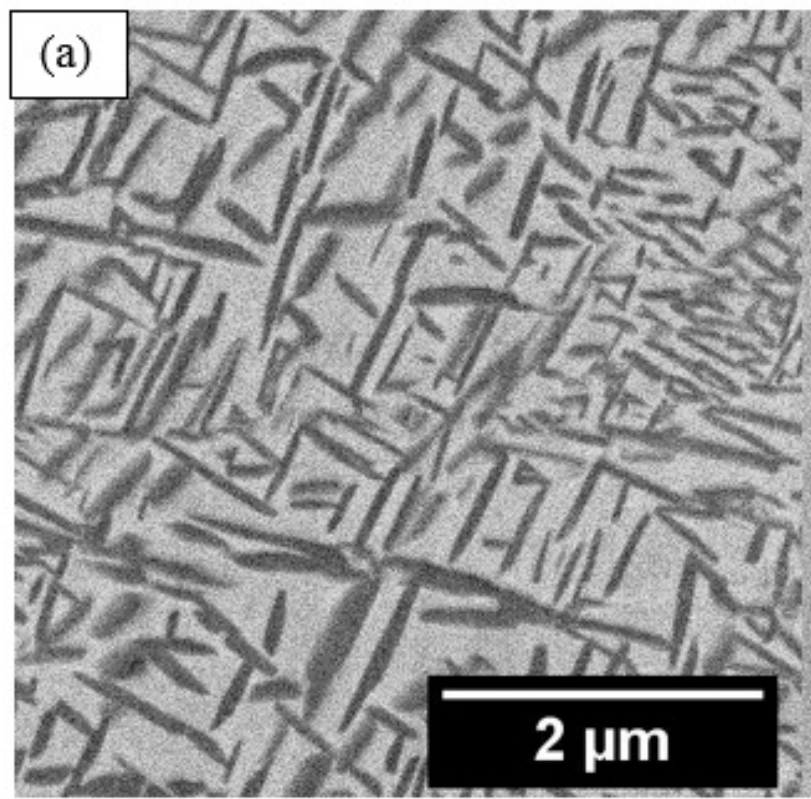

(b)

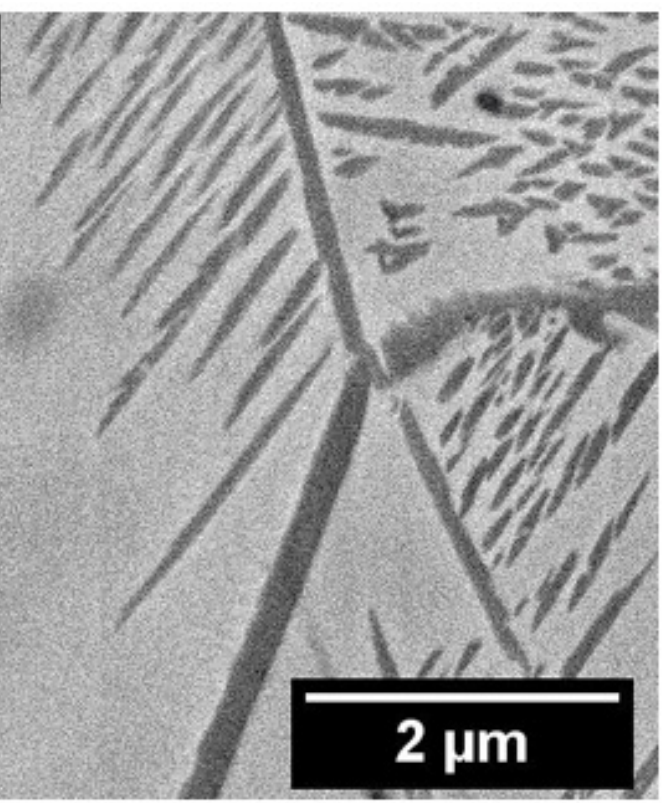

Figure 3. SEM BSE images showing $\alpha$ phase precipitation in Ti-13Mo and Ti-13Mo-6Sn samples after aging at $600^{\circ} \mathrm{C}$ for $1 \mathrm{~h}$, applying a heating rate of $250^{\circ} \mathrm{C} / \mathrm{min}$

Figure 4 shows the Ti-13Mo and Ti-13Mo-6Sn microstructures after heat treatment at $600{ }^{\circ} \mathrm{C}$ for $24 \mathrm{~h}$. In the Ti-13Mo sample, given the extended holding time, $\alpha$ phase precipitation was expected to be very coarse, since there would be enough time for the growth of precipitates. However, this precipitation was not visible in the SEM images. According to Choudhuri et al., the higher the Mo content the less intense the growth of $\alpha$ phase from grain boundaries into the grains [20]. These authors also found 
that high Mo contents increase the number of $\alpha$ phase crystallographic variants. An analysis of the Ti-13Mo-6Sn alloy microstructure revealed highly heterogeneous precipitation. Grain boundary precipitation was found to be very fine, with reduced growth of precipitates in the grains, leading to coarser intragranular precipitation. This led to the inference that, at this aging temperature, the nucleation sites correspond preferentially to grain boundaries.
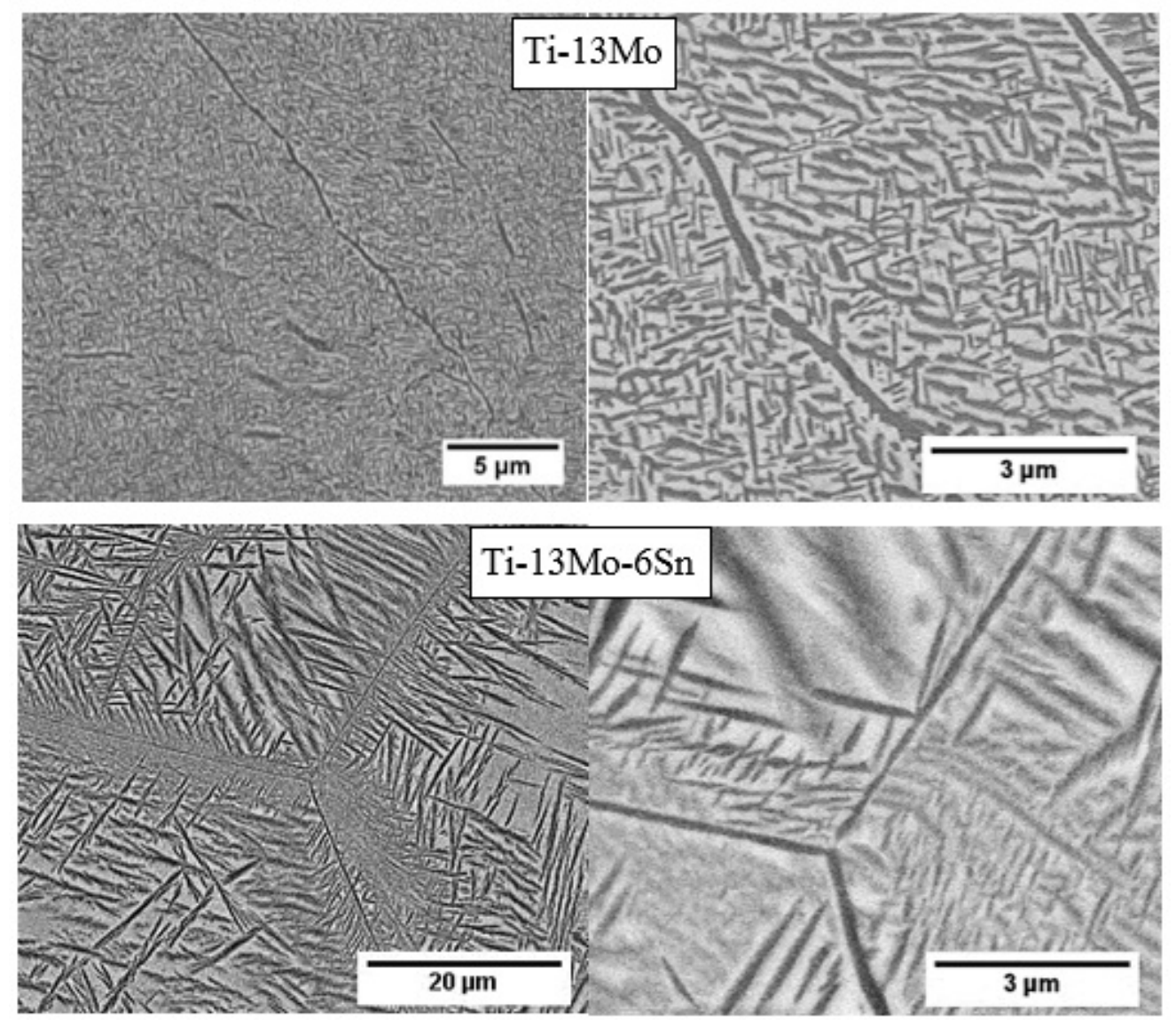

Figure 4. SEM BSE images showing $\alpha$ phase precipitation in Ti-13Mo and Ti-13Mo-6Sn samples after aging at $600{ }^{\circ} \mathrm{C}$ for $24 \mathrm{~h}$, applying a heating rate of $250^{\circ} \mathrm{C} / \mathrm{min}$.

\section{Conclusions}

In summary, it was found that adding Sn to the Ti-13Mo alloy increased the $\beta$ phase lattice parameter after ST/WQ heat treatment. The DSC analyses indicated that the addition of Sn increased not only the $\beta$ transus temperature but also the isothermal $\omega$ phase dissolution temperature. After the aging heat treatment, it was found that the addition of Sn resulted in a microstructure with relatively large and sparse $\alpha$ phase precipitates.

\section{Acknowledgements}

The authors gratefully acknowledge the Brazilian research funding agencies FAPESP (São Paulo Research Foundation), Grant \# 2016/24693-3 and CNPq (National Council for Scientific and Technological Development), Grant \# 405054/2016-5, for their financial support.

\section{$\underline{\text { 6. References }}$}

[1] R.R. Boyer, R.D. Briggs, The Use of $\beta$ titanium alloys in the aerospace industry, J. Mater. Eng. Perform. 22 (2013) $2916-2920$. 
[2] M. Geetha, A.K. Singh, R. Asokamani, A.K. Gogia, Ti based biomaterials, the ultimate choice for orthopaedic implants - A review, Prog. Mater. Sci. 54 (2009) 397-425.

[3] G. Lütjering, J.C. Williams, Titanium, 1a. Ed., Springer-Verlag Press, 2003.

[4] D. Banerjee, J.C. Williams, Perspectives on titanium science and technology, Acta Mater. 61 (2013) 844-879.

[5] Y. Zheng, R.E.A. Williams, D. Wang, R. Shi, S. Nag, P. Kami, J.M. Sosa, R. Banerjee, Y. Wang, H.L. Fraser, Role of $\omega$ phase in the formation of extremely refined intragranular $\alpha$ precipitates in metastable $\beta$-titanium alloys, Acta Mater. 103 (2016) 850-858.

[6] T. Li, D. Kent, G. Sha, L.T. Stephenson, A. V Ceguerra, S.P. Ringer, M.S. Dargusch, J.M. Cairney, New insights into the phase transformations to isothermal $\omega$ and $\omega$-assisted $\alpha$ in near $\beta$-Ti alloys, Acta Mater. 106 (2016) 353-366.

[7] M.Bonisch, M. Calin, T. Waitz, A. Panigrahi, M. Zehetbauer, A. Gebert, W. Skrotzki, J. Eckert, Thermal stability and phase transformations of martensitic Ti-Nb alloys, Sci. Technol. Adv. Mater. 14 (2013) 055004 (9pp).

[8] J.D. Cotton, R.D. Briggs, R.R. Boyer, S. Tamirisakandala, P. Russo, N. Shchetnikov, J.C. Fanning, State of the art in beta titanium alloys for airframe applications, JOM 67 (2015) 1281-1303.

[9] A. George, V. Sharma, R. Divakar, M. Sabeena, E. Mohandas, Transmission electron microscopy studies and modeling of 3D reciprocal space of $\omega$ forming alloy, Micron 102 (2017) 73-87

[10] M.G. De Mello, C.F. Salvador, A. Cremasco, R. Caram, The effect of Sn addition on phase stability and phase evolution during aging heat treatment in $\mathrm{Ti}$ - Mo alloys employed as biomaterials, Mater. Charact. 110 (2015) 5-13.

[11] P.E.L. Moraes, R.J. Contieri, E.S.N. Lopes, A. Robin, R. Caram, Effects of Sn addition on the microstructure, mechanical properties and corrosion behavior of Ti-Nb-Sn alloys, Mater. Charact. 96 (2014) 273-281.

[12] H.M. Rietveld, A profile refinement method for nuclear and magnetic structures, J. Appl. Crystallogr. 2 (1969) 65-71.

[13] L. Lutterotti, S. Matthies, H.-R. Wenk, Combined texture and structure analysis of deformed limestone from time-of-flight neutron diffraction spectra, J. Appl. Phys. 81 (1997) 594-600.

[14] F.F. Cardoso, P.L. Ferrandini, E.S.N. Lopes, A. Cremasco, R. Caram, Ti-Mo alloys employed as biomaterials: Effects of composition and aging heat treatment on microstructure and mechanical behavior, J. Mech.Behav.Biomed.32 (2014) 31-38.

[15] J.C. Williams, B.S. Hickman, D.H. Leslie, The effect of ternary additions on the decomposition of metastable beta-phase titanium alloys, Metall.Trans. 2 (1971) 477-484.

[16] G. Aurelio, A. Fernández Guillermet, G.J. Cuello, J. Campo, Metastable phases in the Ti-V system: Part I. Neutron diffraction study and assessment of structural properties, Metall. Mater. Trans. A 33A (2002) 1307-1317.

[17] W.D. Callister, Materials science and engineering: An introduction, seventh ed.,John Wiley \& Sons, New York, 2007.

[18] M. Carton, P. Jacques, N. Clément, J. Lecomte-beckers, Study of transformations and microstructural modifications in TiLCB and Ti-555 alloys using Differential Scanning Calorimetry, Proc. 11 ${ }^{\text {th }}$ World Conf. Titan. p. 3-6, 2007.

[19] C.F. Yolton, F.H. Froes, R.F. Malone, Alloying element effects in metastable beta titanium alloys, Metall. Trans. A 10A, (1979) 132-134.

[20] D. Choudhuri, T. Borkar, R. Banerjee, D. Banerjee, Mapping the decomposition of $\beta$ to $\alpha$ in composition and temperature space in titanium alloys, Proc. $13^{\text {th }}$ World Conf. Titan, p. 515-519, 2016. 